\title{
Single nucleotide variants of receptor for advanced glycation end-products (AGER) gene: is it a new opening in the risk assessment of diabetic retinopathy?-a review
}

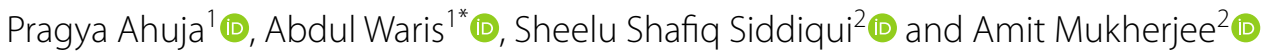

\begin{abstract}
Background: Diabetic retinopathy (DR) is a common microvascular complication of diabetes. There is strong evidence suggesting that DR has an inheritable component. The interaction between advanced glycation end products (AGEs) and their receptor is integral in the pathogenesis of diabetic retinopathy and its various complications, retinopathy being one of them.

Overview and methodology: This review discusses the existing literature on the association between single nucleotide variants (SNV) of AGER gene and the risk of DR. It also discusses the current understanding of the AGE-AGER pathway in diabetic retinopathy. Through our article we have tried to consolidate all the available information about these SNVs associated with diabetic retinopathy in a succinct tabular form. Additionally, a current understanding of the AGE-AGER interaction and its deleterious effects on the cells of the retina has been discussed in detail to provide comprehensive information about the topic to the reader. A literature review was performed on PubMed, Cochrane Library, and Google Scholar for studies to find existing literature on the association between AGER gene SNVs and the risk, progression and severity of developing DR. This article will encourage scientific communication and discussion about possibly devising genetic markers for an important cause of blindness both in developed and developing countries, i.e., diabetic retinopathy.
\end{abstract}

Result: Based on genetic studies done in Indian and Chinese population G82S(rs2070600) was positively associated with Diabetic Retinopathy. Patients of diabetic retinopathy in Caucasian population had -T374A(rs1800624) polymorphism. + 20T/A was found to be associated with the disease in a study done in UK. Association with G1704T(rs184003) was seen in Chinese and Malaysian population. A Chinese study found its association with CYB242T. -T429C(rs 1800625) SNV was not associated with DR in any of the studies. G2245A(rs55640627) was positively associated with the disease process in Malaysian population. It was not associated in Malaysian and Chinese population. Promoter variant rs 1051993 has also been found to a susceptible SNV in the Chinese population.

Conclusion: While providing a comprehensive review of the existing information, we would like to emphasize on a large, multi-centric, trial with a much larger and varied population base to definitely determine these single nucleotide variants predisposing diabetic individuals.

\footnotetext{
*Correspondence: waris_eye@yahoo.co.in; a.waris@amu.ac.in 1 Institute of Ophthalmology, Jawaharlal Nehru Medical College and Hospital, Aligarh Muslim University, Aligarh, Uttar Pradesh, India Full list of author information is available at the end of the article
}

(c) The Author(s) 2022. Open Access This article is licensed under a Creative Commons Attribution 4.0 International License, which permits use, sharing, adaptation, distribution and reproduction in any medium or format, as long as you give appropriate credit to the original author(s) and the source, provide a link to the Creative Commons licence, and indicate if changes were made. The images or other third party material in this article are included in the article's Creative Commons licence, unless indicated otherwise in a credit line to the material. If material is not included in the article's Creative Commons licence and your intended use is not permitted by statutory regulation or exceeds the permitted use, you will need to obtain permission directly from the copyright holder. To view a copy of this licence, visit http://creativecommons.org/licenses/by/4.0/. 
Keywords: Receptor for advanced glycation end products (AGER), single nucleotide variants (SNV), diabetic retinopathy, Gene marker, Risk factor

\section{Introduction}

Diabetes is a global epidemic that is projected to affect 642 million adults by 2040 , with about $75 \%$ residing in low- and middle-income countries [1]. As per the 2019 report of the International Diabetic Federation, 351.7 million people of the working-age group (20 to 64 years) have been diagnosed or suspected to have diabetes in 2019 [2]. It is estimated that every third patient with diabetes has some form of diabetic retinopathy (DR) [3]. DR is emerging as a significant non-communicable disease leading to ocular morbidity. Its increased prevalence in the working-age group up to 50 years leads to poor quality of life and decreased psychosocial well-being [4]. So a careful understanding of the pathophysiology of this disease is imperative to help predict the future course of the disease and its associated complications.

Duration of diabetes is a significant risk factor for the development of DR. It develops in $2 \%$ of patients having type 2 diabetes for less than 5 years and in $25 \%$ of patients having the disease for 25 years or more [5]. However, once retinopathy develops in the patient, glycemic control becomes the most crucial factor in determining the course of the disease and helps control micro-vascular complications of type 2 diabetes mellitus [6].

Despite providing robust evidence for susceptibility to diabetic retinopathy, environmental risk factors do not account for complete risk susceptibility. In the DCCT trial, major environmental factors, glycosylated hemoglobin, and duration of diabetes explained only $11 \%$ of the variation in the risk of retinopathy [7]. In the WESDR study, a combination of three environmental factors, i.e., glycosylated hemoglobin, blood pressure and total cholesterol, could explain only a $10 \%$ variation in the risk of diabetic retinopathy [8]. Despite having reasonable glycemic control and a short duration of diabetes, some patients developed diabetic retinopathy later. While others with poor glycemic control and long duration of diabetes did not develop DR. $[9,10]$ All these factors thus raise the possibility of genetic factors determining the predisposition to diabetes and its severity. Previous studies demonstrating familial clustering of DR cases further reinforce the role of genetic factors in the pathogenesis of diabetic retinopathy [10]. DR is a complex multigenic interactive process, and any alteration in the genes related to various biochemical pathways is hypothesized to contribute to the development of DR.

AGEs are heterogeneous molecules formed by the non-enzymatic reaction of glucose-derived carbonyls with amino groups of amino acids. AGER binds to and internalizes low levels of AGEs for degradation in normal individuals. However, in people with diabetes, due to increased production and mutation in the $A G E R$ gene, there is an accumulation of AGEs. The interaction between AGEs and their receptor is integral in the pathogenesis of DR. When stimulated chronically, it triggers a downstream signalling cascade that causes the release of cytokines, chemokines, and growth factors-like VEGF. These act collectively and damage the cells of the retina. Through this article we aim to study single nucleotide variants (SNVs) and their association with the progression and severity of diabetic retinopathy. Any polymorphism in the gene for this receptor will alter this pathway and have an influence on the pathophysiology of diabetic retinopathy. Many researches have been done to determine these specific SNVs, which have further demonstrated a demographic and ethnic variation in their results. Through our article we have tried to consolidate all the available information about the SNVs associated with diabetic retinopathy in a succinct tabular form. Additionally, a current understanding of the AGE-AGER interaction and its deleterious effects on the cells of the retina has been discussed in detail to educate the reader about this topic as a whole. This article will encourage scientific communication and discussion about possibly devising genetic markers for this disease. To conclude, while providing a comprehensive review of the existing information, we would like to emphasize on a large, multi-centric, trial with a much larger and varied population base to definitely determine these single nucleotide variants predisposing diabetic individuals.

\section{Methods \\ Identification of source}

PubMed, Cochrane Library, Google Scholar, Embase, MEDLINE databases were searched extensively for the research studies in English, presenting outcomes on the study of various Single nucleotide variants (SNVs) of $A G E R$ gene and their association with the development and progression of DR.

\section{Method of evaluation}

A critical assessment of the literature was performed. Preference was given to high-quality (high citation) papers, meta-analysis, longitudinal trials, and randomized control studies performed with correct statistical analysis and accurate methodology. 


\section{Pathophysiology of diabetic retinopathy Role of oxidative stress}

Oxidative stress induced by hyperglycemia plays a vital role in the pathogenesis of diabetic retinopathy. Altered expression of pro-inflammatory cytokines and interrelated pathways has been observed in retinal blood vessels. In the absence of an appropriate and effective endogenous antioxidant defence system, excessive reactive oxygen species (ROS) accumulation leads to activation of stress-sensitive intracellular signalling pathways, all of which promote cellular damage and diabetic complications [11]. Oxidative stress causes activation of various biochemical pathways, the polyol pathway, aldose reductase and protein kinase pathway. It also increases hexosaminidase pathway reflux and is associated with increased advanced glycation end product (AGE) formation $[12,13]$. The conversion of glucose to sorbitol and fructose via the polyol pathway in chronic hyperglycemic conditions decreases intracellular antioxidant agents like NADPH and GSH [14].

Subsequent ROS accumulation inhibits glucose6-phosphate dehydrogenase (G6PD) enzyme, which is necessary to reduce equivalents for the antioxidant system, thereby amplifying the oxidative stress. Further accumulation of NADH inhibits glyceraldehyde-3-phosphate, thereby increasing the precursors of the AGE pathway. This ultimately causes downstream activation of pyruvate kinase C. Chronic hyperglycemia not only activates these biochemical pathways, it also increases the levels of various cytokines, growth factors, endothelin-1 and angiotensin-2 of the RAAS system. The pyruvate kinase pathway is also activated, ultimately leading to hyperglycemia-induced cellular damage by inducing various chemical mediators. All these mechanisms lead to accelerated vascular damage associated with diabetes, leading to various macro- and micro-angiopathic complications like retinopathy, neuropathy and nephropathy [14]. Even though strict glycemic control can delay the effect and progression of diabetic retinopathy, it cannot stop its progression. This causes long-lasting damage to tissues even after glycemic control is achieved (Fig. 1).

\section{Advanced Glycation end products (AGEs)}

Advanced Glycation End products (AGEs) are heterogeneous molecules formed by the non-enzymatic reaction of glucose-derived carbonyls with amino groups of unprotonated lysine and arginine protein residues through a series of reactions forming Schiff bases and Amadori products [15]. This is a concentration dependant reaction in its early stages than later, thus explaining their increased formation in people with diabetes (Fig. 2).

AGEs and their intermediates usually accumulate in retinal blood vessels, glial cells, and neurons with age
[15]. However, this deposition occurs at a faster rate in people with diabetes due to hyperglycemia, oxidative stress, and inflammation [16].

Over 20 different AGEs have been described to date, of which major groups are carboxymethyl lysine (CML), carboxyethyl lysine (CEL), pentosidine, glucosepane, methylglyoxal lysine dimer (MOLD), glyoxal lysine dimer, and glycolic acid lysine amide [15]. Hyperglycemia induced ROS overproduction is caused due to attachment of AGE to its receptor. Chronic hyperglycemia causes increased intracellular glucose accumulation causing glucose conversion to glyoxal while transforming the Amadori products to deoxyglucasone and producing methyl-glyoxal by fragmentation of glyceraldehyde 3-phosphate and dihydroxyacetone phosphate (DHAP) [17]. The majority of damage caused by AGEs is by glycolytic intermediates like glyoxal, methylglyoxal, and 3-deoxyglucose (3-DG). 3-Deoxyglucose is formed by non-oxidative rearrangement and hydrolysis of Amadori adducts and forms intermediates of the polyol pathway. In contrast, methylglyoxal is formed by the non-oxidative pathway of anaerobic glycolysis and oxidative decomposition of PUFA, fructose, ketone body catabolism, and amino acids like threonine $[18,19]$. All these AGE intermediates then react with intracellular and extracellular proteins to form advanced glycation end products.

Not only diabetes, the role of AGEs has also been seen in male erectile dysfunction, pulmonary fibrosis, Alzheimer's disease, reduced elasticity of the skin, and end-stage renal disease (ESRD), to name a few [20]. Histopathological studies have shown AGEs to accumulate in the kidney's basement membrane causing glomerulosclerosis, coronary atheromas in atherosclerosis, amyloid-beta plaques of Alzheimer's disease, and cartilage of rheumatoid arthritis [18].

AGEs like carboxyethyl-lysine (CEL), carboxymethyllysine (CML), and pentosidine have been localized in the retinal blood vessels, neurons, and glial cells of diabetic patients, and their levels were found to correlate with the degree of retinopathy $[12,21]$. The accumulation of dicarbonyl, glycoxidation, or lipoxidation precursors forms either oxidative AGEs like CML and pentosidine or non-oxidative AGEs like DOLD (deoxy glucasone lysine dimer) from 3-deoxyglucose and MOLD (methyl glyoxal lysine dimer) from methylglyoxal. This phenomenon is called carbonyl stress and has been explained as one of the many pathological mechanisms responsible for accelerated vascular damage in diabetes [18].

Hyperglycemia induced ROS overproduction is mediated by AGEs interaction with its receptors like AGE-R1 (oligosaccaharyl transferase-48), 80K-H phosphoprotein (AGE-R2) AGER1/2/3, Galectin-3 (AGE-R3), CD36, and macrophage scavenger receptor (MSR-1 and 


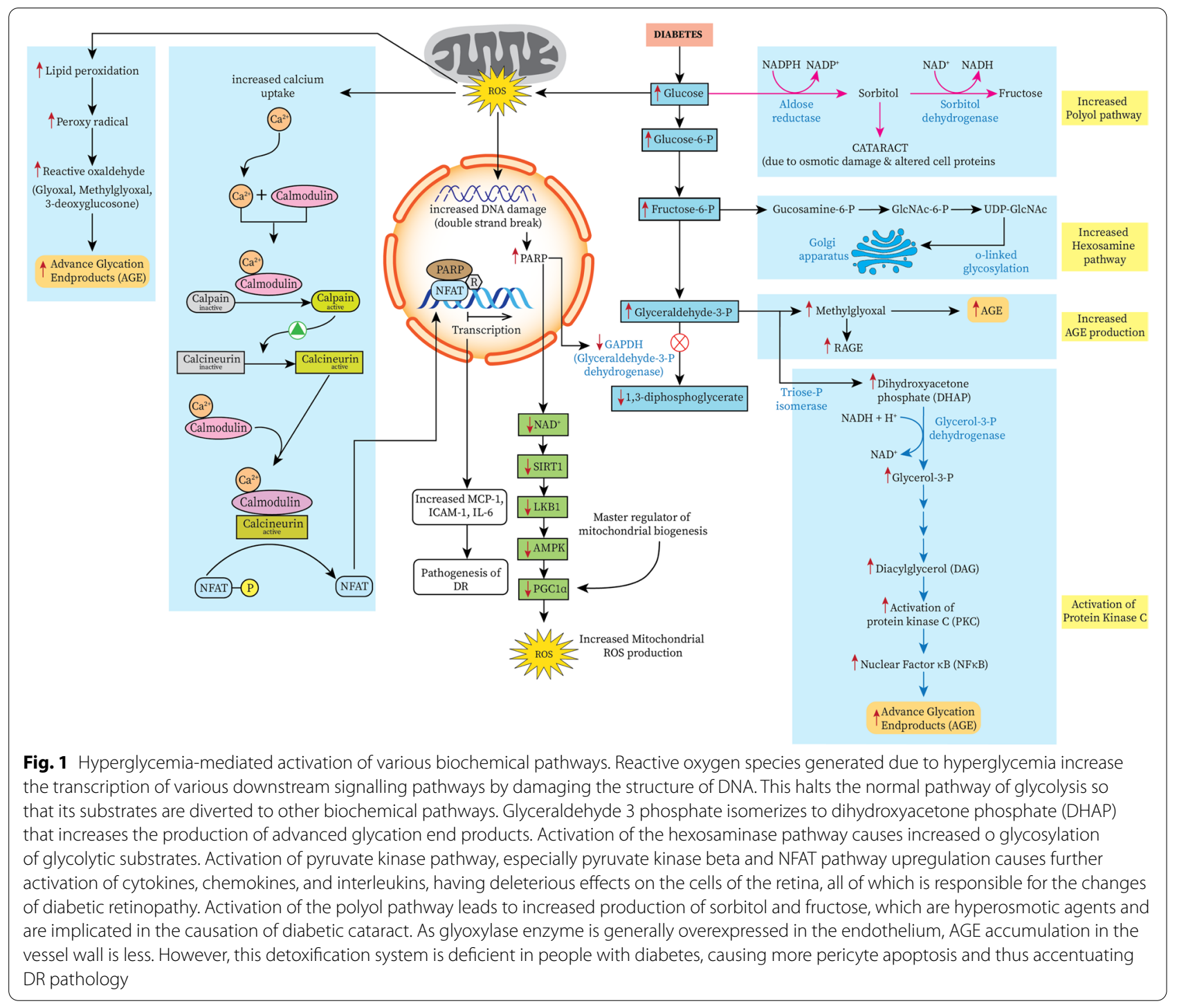

2) is implicated in the pathogenesis of diabetic retinopathy $[14,22]$.

\section{Receptor for advanced glycation end-products (AGER):}

$A G E R$ is a multiligand member of the immunoglobulin superfamily [23]. Its truncated form, $35 \mathrm{kD}$ transmembrane protein is expressed in many body cells like beta cells of the pancreas, lymphocytes, monocytes, neuronal cells, and endothelial cells in various tissues like the lung, liver, smooth muscle, endothelial cells, and brain $[24,25]$. It acts as a scavenger and mediates intracellular signalling.

AGER has several distinct protein domains. The extracellular region where the following two domains form an integrated structural unit has a V type domain consisting of 96 amino acids and a $\mathrm{C} 1$ domain having 97 amino acids. The $\mathrm{C} 2$ domain having 90 amino acids, is a fully independent unit. It has a transmembrane domain with 20 amino acids that anchors $A G E R$ to plasma proteins, thereby helping in transducing signals to the cell interior. A highly charged short cytoplasmic domain having 43 amino acids has endogenous kinase activity and is responsible for intracellular signalling. A flexible linker protein connects the extracellular domain and $\mathrm{C} 2$ domain [26].

$A G E R$ exists in various functional variants, each of which has a tissue-specific regulation of expression. These are formed by alternative splicing or by the action of membrane-associated proteases. The fulllength AGER (fl AGER) is also called membrane-bound $A G E R$ (mAGER). Its $N$ terminal truncated isoform does 

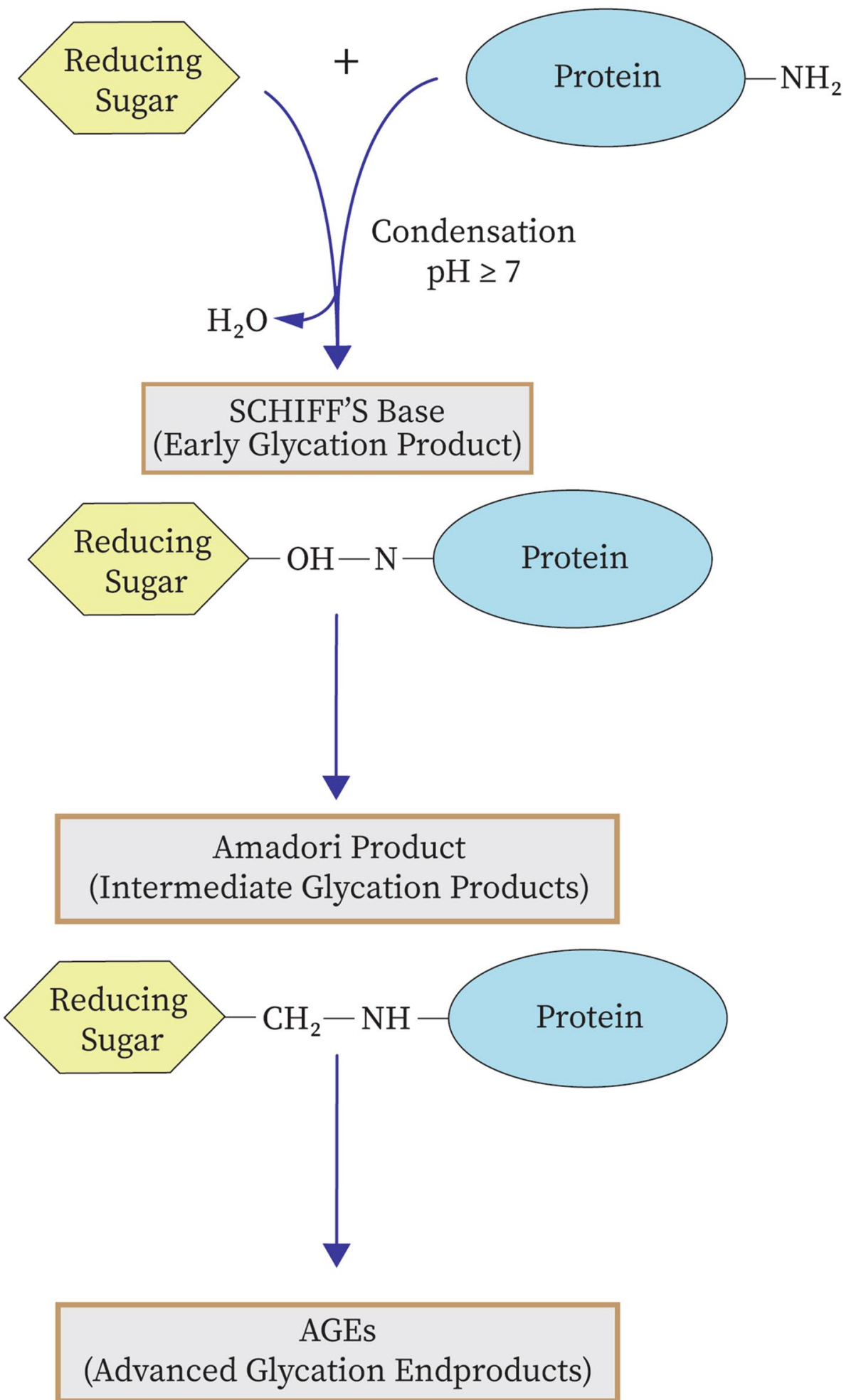

Fig. 2 Maillard reaction for the formation of advanced glycation products 
not have a V domain, because of which it cannot activate the downstream signalling pathway. Instead, due to its ability to bind to $\mathrm{m} A G E R$, it may dampen its effect. This truncated form is also termed tail deletion or Dominant-negative AGER (Dn-AGER) [23, 27]. Soluble AGER (sAGER) is the C terminal truncated secretory isoform of receptor for advanced glycation end products. It is produced by alternate splicing of its encoding DNA at exon nine called endogenous secretory AGER (esAGER) or by the proteolytic cleavage of cell surface-bound $m A G E R$ [28, 29]. Since it lacks a transmembrane and cytosolic domain, it can be released into circulation easily. As AGER expression is increased by AGEs, its concentration is commonly used to indicate $A G E R$ gene expression in tissues. It scavenges $A G E R$ ligands and is responsible for the downstream signalling mediated by mediators like NFkB, SP-1, and AP-2 [26, 30].

The human gene for receptor of AGEs (AGER) is located on the short arm of chromosome 6 , on locus 6p21.3 of MHC-III [31]. It has a 1.7-kb 5' flanking region and 11 exons, 10 introns, and about 20 splice variants due to alternate splicing $[23,32]$. Its $5^{\prime}$ flanking region regulates transcription. Apart from AGEs, AGER also binds to many different ligands like CML, S100s like S100A12, also called as (En-AGER), A-beta oligomers, HMGB1, LPA, CD11b/Mac1, C3a, which bind to V domain; A-Beta aggregates bind to the $\mathrm{C} 1$ domain and S100 A-Beta, which binds to the $\mathrm{C} 2$ domain in a dose-dependent manner [21, 27]. Not only is $A G E R$ production upregulated by these ligands, but also there is increased activation of the downstream signalling pathway mediated via various cytokines [33].

$A G E R$ expression is upregulated in many diseases like Alzheimer's disease, diabetes mellitus, atherosclerosis, and rheumatoid arthritis [16, 34].

$A G E R$ binds to and internalizes low levels of AGE for degradation in normal individuals, thus protecting us from its deleterious effects. However, in people with diabetes, due to increased production and mutation in the gene for receptor of advanced glycation end products, there is an accumulation of AGE and receptor-mediated activation and secretion of various cytokines. These cytokines activate various signal transduction pathways like protein kinase C, JAK-STAT tyrosine phosphorylation, $\mathrm{PI} 3^{\prime} \mathrm{K}$ recruitment to RAS, which creates a positive feedback loop responsible for long term side effects of hyperglycemia via increased NFkB and AP-1 transcription [32, 35]. Levels of glyoxylase enzyme (GLO1), responsible for AGE detoxification, are reduced in aged and diabetic tissues.

AGEs cause damage to target cells and cause a plethora of complications by many mechanisms:

\section{AGE-AGER interaction on extracellular matrix (ECM)}

As advanced glycation is a slow process, it generally affects long-lived proteins like those of the extracellular matrix (ECM) and basement membrane. Altered AGE modification of sub-endothelial ECM components like collagen and laminin alters their interaction with other matrix proteins, and integrin receptors like integrin $\alpha 2 \beta 1$ [36] such that they do not respond to biological signals anymore. AGE acts on the intercellular junctions between various extracellular molecules formed by occludin, claudin and zonula occludens family and adhering junctions mediated by VECadherin, affecting the junctional complexes stability. This affects the integrity of the blood-retinal barrier and makes the vessels leaky [37]. Sometimes, altered extracellular matrix components due to covalent cross-linking traps the circulatory proteins, affecting cellular traffic and cause narrowing of vessel lumen leading to vasculopathy $[18,38]$. All these mechanisms get amplified due to increased AGE$A G E R$ interaction, such that normal effector cells cannot perform reparative functions (Fig. 3).

\section{AGE-AGER mediated release of various cytokines and ligands}

AGEs decrease the elasticity of blood vessels and deplete Nitric Oxide (NO), which has endothelium-dependent vasodilatory and anti-proliferative effects on the vascular smooth muscle [18]. Increased expression of intracellular $A G E R$ s and its major endogenous ligands is seen, which bind to each other and induce receptor-mediated production of deleterious gene products like ROS, NF-kB, and AP1 [24]. It also leads to increased production of cytokines like TNF- $\alpha$, Interleukin- $1 \beta$, and Interleukin- $1 \alpha$, thus responsible for hyperpermeability and growth factors like vascular endothelial growth factor (VEGF) [14, $27,39]$. Interleukin recruitment causes microglial activation and monocyte infiltration in the diabetic retina [40]. It has been hypothesized that AGE-AGER interaction causes VEGF over-expression by NADPH oxidase mediated ROS production, which further causes activation of redox-sensitive transcription factor NF-kB via the RAS-MAP kinase pathway [15, 40]. NF-kB modulates various genes like IL-6, TNF- $\alpha$, ICAM-1, VCAM-I, and monocyte chemotactic protein-I (MCP-I) [22, 24]. Upregulation of VEGF causes endothelial mitogenesis, neovascularization and vascular leakage due to increased endothelial permeability [41].

\section{AGE-AGER interaction has a pro-coagulant effect}

AGEs on attaching to the cell contribute to increased vascular permeability, pro-coagulant activity, and adhesion molecule expression. There is reduced platelet survival, increased platelet aggregation and altered 

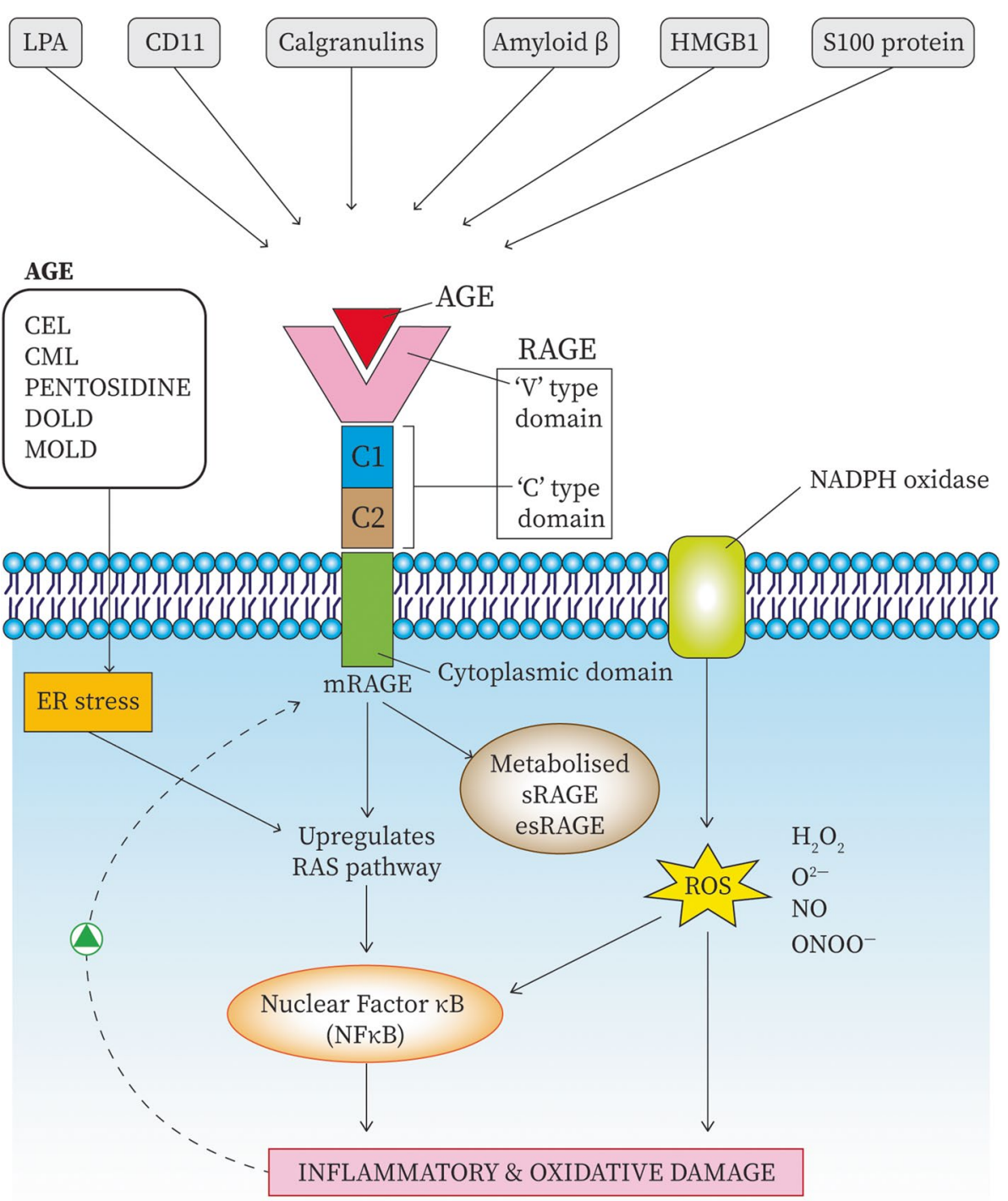

Fig. 3 Receptor for AGE interacts not only with AGEs but also with other ligands like LPA, CD11, calgranulins, amyloid beta, HGMB1, and S100 protein. The interaction of AGEs with AGER initiates a downstream signalling cascade. The primary mediator for the inflammatory pathway is the ultimate induction of $\mathrm{NFkB}$, which causes oxidative and inflammatory damage. Hyperglycemia associated oxidative ER stress and reactive oxygen species production induce NFkB. This inflammatory and oxidative damage thus caused creates a positive feedback loop causing further AGER activation

levels of coagulation factors like anti-thrombin 3, tissue factor, thrombomodulin, and fibrinolytic inhibitor plasminogen-activator inhibitor-1(PAI-1) [42]. Various intracellular adhesion molecules, as mentioned above get activated due to AGEs and cause adhesion and transmigration of leucocytes to the endothelium. This leads to oxidative stress due to further polymorphonuclear leucocyte (PMNL) recruitment. When this cycle happens multiple times, there is endothelial loss and more activation of platelets and fibrin at that time [37]. These patients have alterations in von williebrand factor (vWf) , platelet function, and coagulation factors like factor VII [25]. All these contribute to the development of a procoagulant hypoxic state, thus contributing to the development and progression of vascular complications [24].

\section{AGE-AGER interaction's effect on oxidative stress}

On the one hand, AGEs increase reactive oxygen species (ROS) formation, while ROS also induces formation 
of AGEs. Their receptor binding causes tyrosine phosphorylation of JAK-STAT signal transducers, recruitment of phosphatidyl inositol $3^{\prime}$ kinase (PI3K) to RAS, and protein kinase $\mathrm{C}$ (PK-C) activation. Under normal conditions, $A G E R$ upregulation inhibits the activity of $\mathrm{NADPH}$ oxidase which decreases the formation of ROS. However due to persistent, long term exposure to AGEs $A G E R$ expression is altered because of which there is an increase in inflammation and oxidative stress [19].

\section{Pathogenesis of AGE-AGER interaction}

AGEs are toxic to retinal capillaries [43]. They induce retinal pericyte apoptosis, osteoblastic differentiation, and calcification [37, 44, 45]. Vascular leakage is seen in these patients due to its increased endothelial permeability, pericyte loss, and pro-coagulant effect [22].

Muller cells contribute to the regulation of vital features of early retinal vasculature like homeostasis and vascular permeability. Due to the increased expression

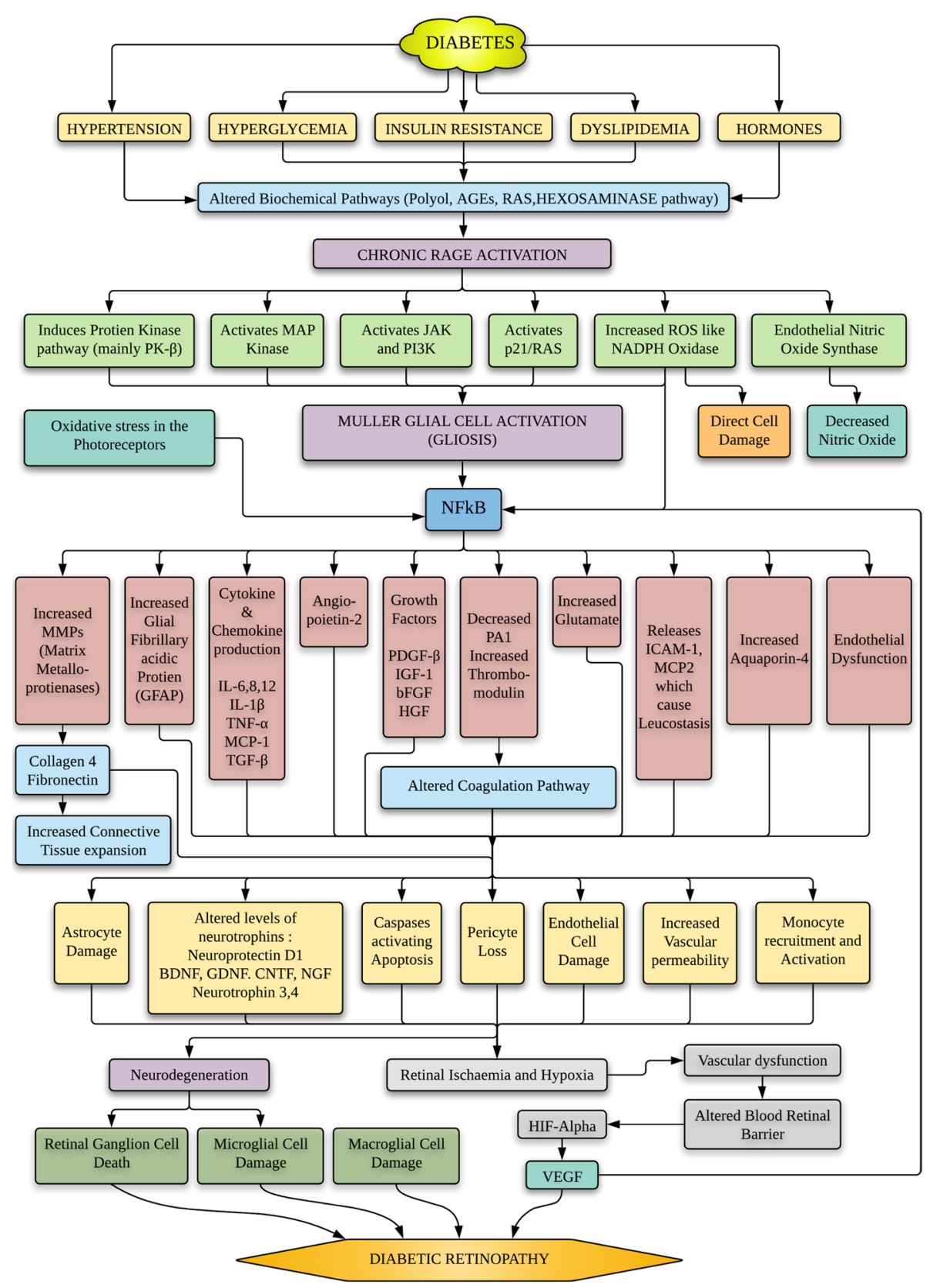

Fig. 4 Downstream cascade of various chemokines, cytokines, and inflammatory mediators that causes damage to various retinal cells causing diabetic retinopathy 
of $A G E R$ in these cells in people with diabetes compared to non-diabetics, muller cells are hypothesized to act as a regulator of diabetic retinopathy [46].

Microvascular changes like vessel wall thickening and pro-coagulant effect cause vaso-occlusion and induction of growth factors like VEGF, which leads to angiogenesis and neo-vascularization. The release of angiogenic growth factors like VEGF destroys the blood-retinal barrier causes retinal edema, neovascularization, hemorrhages, micro-aneurysms, and vessel occlusion. Recruitment of monocytes to sites of AGE accumulation brings about further endothelial dysfunction [37].

$A G E R$-mediated cellular stimulation and ligand receptor activation leads to creation of a positive feedback loop thereby causing an increased expression of the receptor and thereby amplifying its downstream AGER-mediated signalling cascade. Thus, to put a stop to this cycle, mechanisms need to be devised to stop ligand binding to the receptor [27].

Inherited differences, mutations, and polymorphisms in key regions of the $A G E R$ gene may play an important role in AGE-AGER binding and altering their downstream signalling pathway, thus altering the future course of this disease [16, 35] (Fig. 4).

Over 30 polymorphisms are known in the AGER gene, most of which are Single nucleotide variants (SNVs), leading to altered function and expression of $A G E R$ if present in its regulatory region. It is essential to understand which of these gene variants is associated with the development of retinopathy as knowledge of these might help in its early detection in patients with specific SNVs, devise rapid diagnostic kits, and formulate therapeutic plans in the future. Many studies have been done to correlate the association between DR with genetic polymorphism in the $A G E R$ gene, but all these studies have had inconsistent results. A systematic assembly of the various $A G E R$ gene polymorphisms that have been studied and their variation with ethnicity will help us localize which polymorphisms are associated with the pathogenesis of diabetic retinopathy Table 1 .

\section{Unanswered questions and future needs}

Although there is strong evidence to suggest that DR is a heritable trait none of these polymorphisms have however received widespread public acceptance due to the polygenic and multifactorial nature of DR, in addition to the influence of various environmental factors. Insufficient sample sizes with inadequate phenotypic characterization of subjects to explain diabetic retinopathy is the reason for limited success in this field. Further prospective studies with some standardizations of phenotypic variables are necessary to confirm the association between SNV in the RAAGE gene and pinpoint which specific SNVs are associated with an individual's predisposition to diabetic retinopathy and the progression of its severity. It will also help in further understanding the influence of ethnic background on this association. This polymorphism study may also help us understand the precise pathogenic mechanisms involved with DR. Not only will this specific polymorphism help diagnose such high-risk patients, but it will also help in devising specific gene therapies for such high-risk subjects in the coming future. This might help halt the onset and progression of the disease and could be a path-breaking development in our attempt to save the world from blindness due to DR.

\section{Conclusion}

Receptor of advanced glycation end products gene on chronic stimulation by hyperglycemia acts at transcriptional level, to release various proinflammatory interleukins, chemokines and growth factors. This damages the glial cells in the retina and cause pericyte apoptosis and extensive endothelial vascular damage.

Based on genetic studies done in Indian and Chinese population G82S(rs2070600) was positively associated with Diabetic Retinopathy. Patients of diabetic retinopathy in Caucasian population had -T374A (rs1800624) polymorphism. $+20 \mathrm{~T} / \mathrm{A}$ was found to be associated with the disease in a study done in the UK. Association with G1704T(rs184003) was seen in Chinese and Malaysian population. A Chinese study found its association with CYB242T. -T429C(rs1800625) SNV was not associated with DR in any of the studies. G2245A(rs55640627) was positively associated with the disease process in Malaysian population. It was not associated in Malaysian and Chinese population. Promoter variant rs1051993 has also been found to a susceptible SNV in the Chinese population.

Despite the comprehensive work and analysis done on finding the association between AGER gene SNV and DR risk, none of the identified polymorphisms have achieved widespread acceptance as a marker of high risk of diabetic retinopathy. These studies still have limitations and should be interpreted cautiously. The discrepant findings might be due to the differences in the statistical power, demographic variations, type of diabetic retinopathy, and the genetic and environmental background. Diabetic retinopathy is a multigenetic and multifactorial disease. Most of the studies included here were cross sectional studies, so the influence of $A G E R$ gene SNVs on the progression of DR was difficult to assess. Our $A G E R$ gene SNV analysis not only provides a deeper understanding of diabetic retinopathy pathogenesis, but also implies novel targets for DR gene therapy. The application of pharmacogenetic principles appears to be a promising strategy in attenuating the diabetes mellitus-mediated 


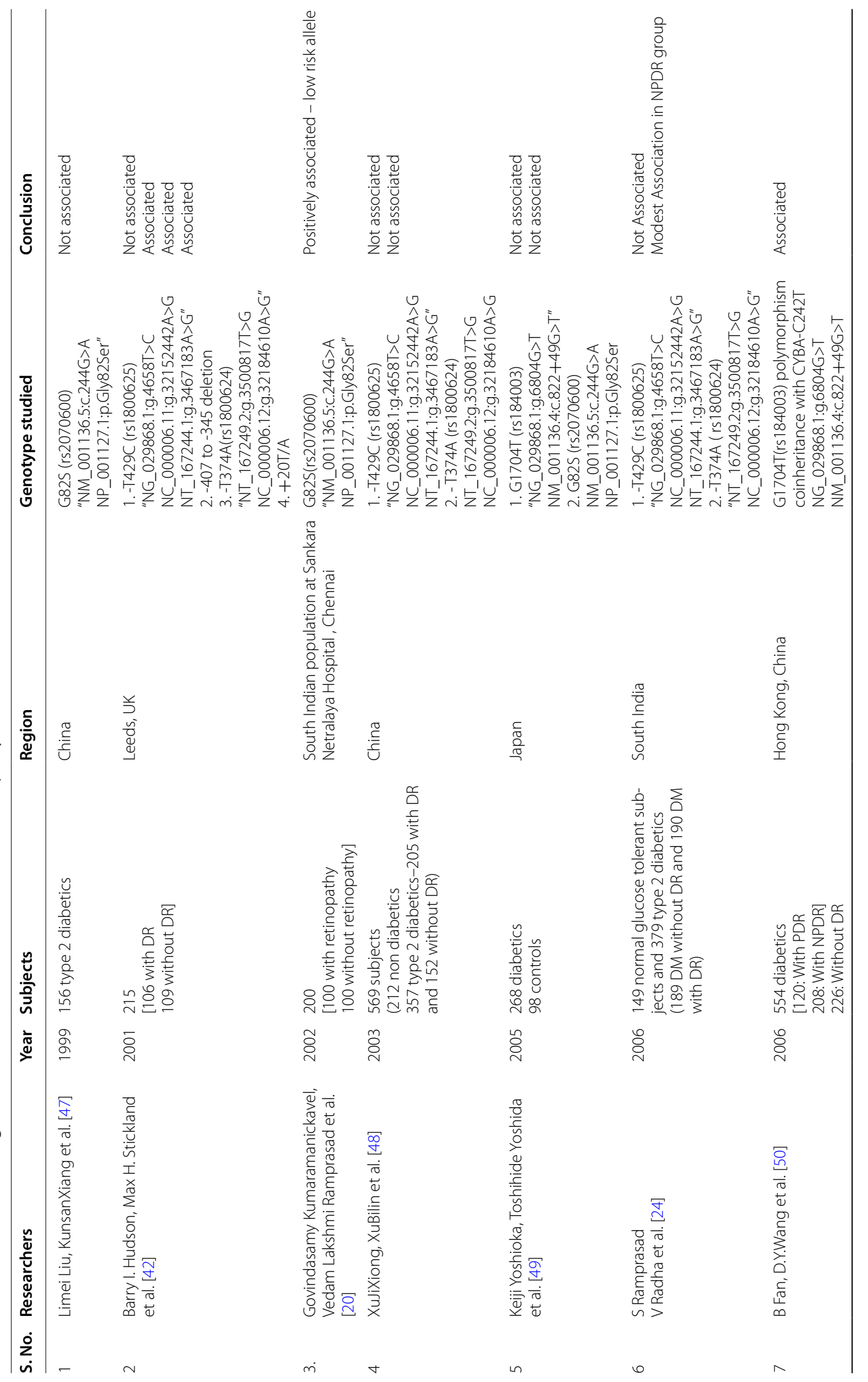




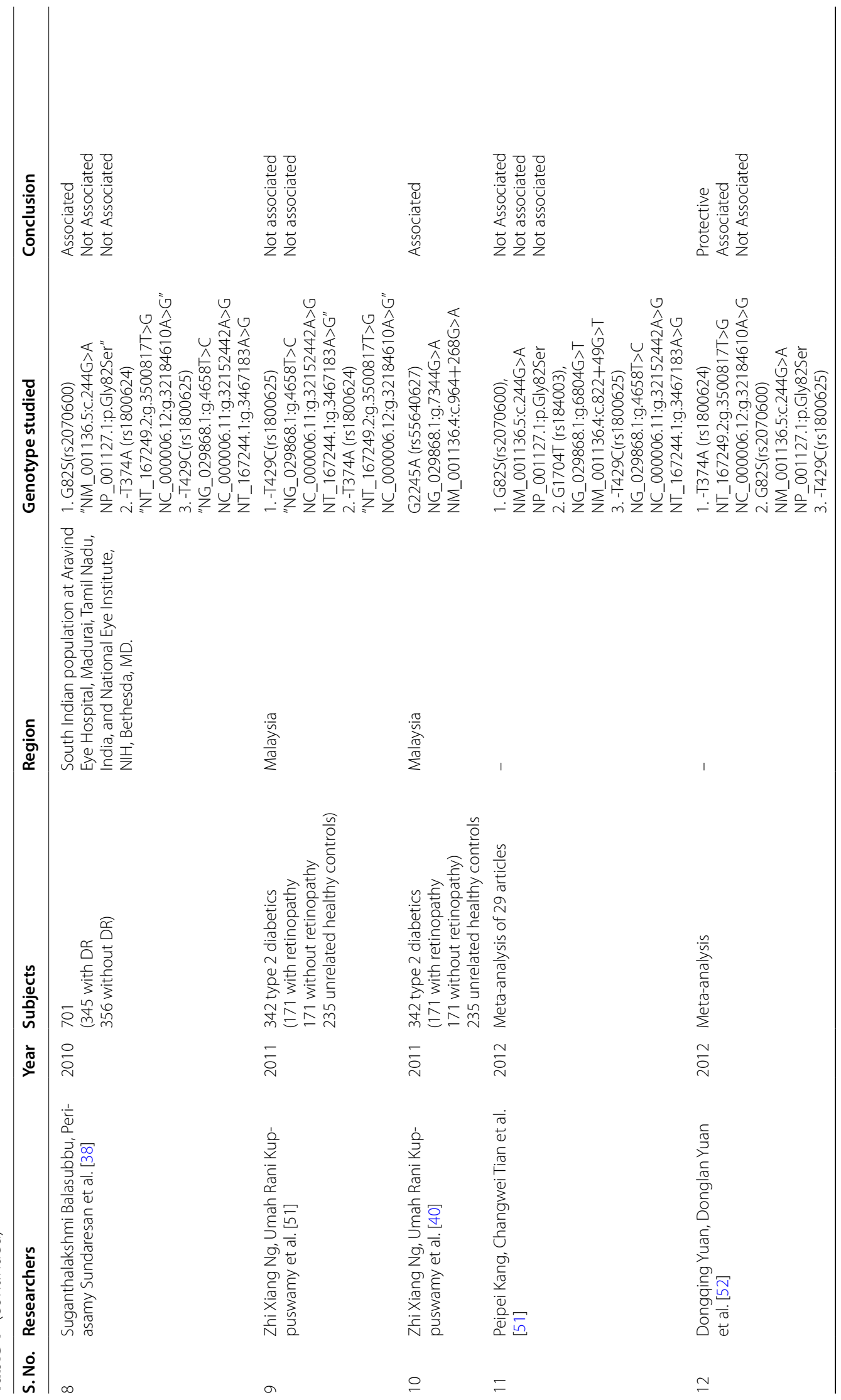




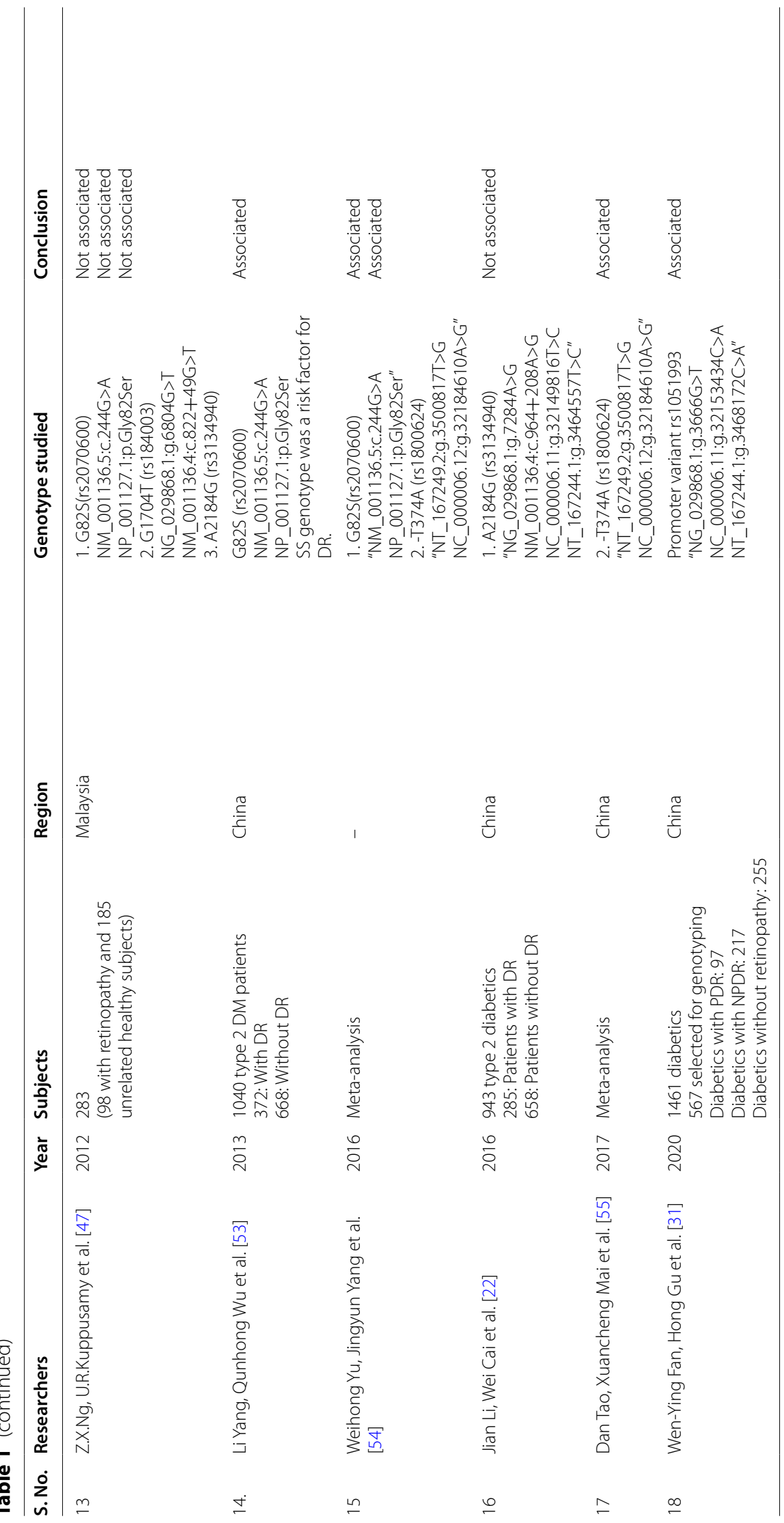


retinal vascular complications. Genetic marker screening will help identify the people at risk, slowing the disease progression and help reduce the micro-vascular complications, disability, and mortality rates.

Given the increase in DR incidence and presence of multiple research centers, uniform guidelines need to be devised for data collection and genetic analysis as a part of the larger collaboration between different countries representing varied ethnic groups. It is hoped that over the next few years, promising therapies need to be evaluated in clinical context, thereby reducing the medical and economic burden of DR and its associated blindness.

\begin{abstract}
Abbreviations
1,3-BPG: 1,3-Biphosphoglycerate; ADP: Adenosine diphosphate; AMP:

Adenosine mono phosphate; DAG: Diacyl glycerol; DHAP: Di-hydroxy acetone phosphate; DNA: Deoxyribonucleic acid; DR: Diabetic retinopathy; ECM: Extracellular membrane; eNOS: Endothelial nitric oxide synthase; ERK-1/2: Extracellular signalling regulated protein kinase; GADPH: Glyceraldehyde-3 phosphate dehydrogenase enzyme; GFAT: Glutamine fructose-6-phosphate transaminase; Glc-6-P: Glucosamine-6-phosphate; GlcNAc-6-P: N-Acetylglucosamine-6-phosphate; HIF-alpha: Hypoxia inducible factor-1-alpha; ICAM-1: Intracellular cell adhesion molecule; IGF: Insulin-like growth factor; IL-1,6: Interleukins; iNAD: Intracellular nicotinamide adenine dinucleotide; JAK: Janus kinase; LKB-1: Liver kinase B1; MAP kinase: Mitogen-activated protein kinase; NFAT: Nucleic factor of activated T cells; NADP ${ }^{+}$: Nicotinamide adenine dinucleotide phosphate; $\mathrm{NADPH}$ : Reduced nicotinamide adenine dinucleotide phosphate; NADPH oxidase: Nicotinamide adenine dinucleotide phosphate oxidase; NFkB: Nuclear factor kappa B; NO: Nitric oxide; 0-Glc: O-linked glucosamine; p21RAS: RAS p21 protein activator-1; PA-I: Plasminogen activator inhibitor-1; PARP-1: Poly ADP ribose polymerase-1; PDGF- $\beta$ : Platelet-derived growth factor- beta; PI3K: Phosphoinositide-3-kinase; PK- $\beta$ : Pyruvate kinase-beta; PPAR-alpha-1: Peroxisome proliferator-activated receptor gamma cofactor-1-alpha; AGER: Receptor for advanced glycation end products; ROS: Reactive oxygen species; SIRT-1: Sirtuin-1; SNV: Single nucleotide variants; TCA: Tri-caboxylic citric acid cycle; TGF- $\beta$ : Transforming growth factor beta; TLR4: Toll-like receptor 4; TNF-alpha: Tumor necrosis factor-alpha; UDP-GlcNAc: Uridine diphosphate N-acetyl glucosamine; VCAM-1: Vascular cell adhesion protien-1; VEGF: Vascular endothelial growth factor.
\end{abstract}

\section{Acknowledgements}

We would like to acknowledge our Head of Department (Institute of Ophthalmology, JNMCH, AMU, Aligarh), Prof. M Ashraf sir was always providing us with a guiding hand.

\section{Authors' contributions}

AW and SSS conceptualized and designed the article and gave the final approval for this version of the article to be published. PA was responsible for data collection and was the major contributor in writing this manuscript. AM critically revised the article. PA and AM prepared the illustrations for this article. All authors have approved the manuscript and agree to its submission to the "Journal of Genetic Engineering and Biotechnology".

\section{Author's information}

Dr. Abdul Waris is a Vitreo-Retinal Consultant trained in pediatric, refractive, and anterior segment surgery. He has more than 8 years of teaching experience in Medical College and has over an experience of over 20 years in Ophthalmology having worked in many countries all over the world. A sincere and motivational teacher, he has published and supervised publishing of research papers in multiple indexed journals and continues to strive for excellence. He currently runs Vitreo-Retina Clinic at Institute of Ophthalmology, JNMCH, AMU. His particular area of interest is in diabetic retinopathy and he is actively involved in guiding post graduate students in research work. He is also the deputy medical superintendent of the hospital and takes care of the functioning of the boys hostel at JNMCH as well.
Dr. Sheelu Shafiq Siddiqui is currently the director at Rajiv Gandhi Centre for Diabetes and Endocrinology, Faculty of Medicine, Jawaharlal Nehru Medical College, Aligarh Muslim University, Aligarh. His particular areas of interest include diabetes and its associated complications. He is actively involved in research work and has guided many students for research work under him. Dr. Pragya Ahuja is currently a second year junior resident doing her masters in surgery course in Ophthalmology from Institute of Ophthalmology, Jawahar Lal Nehru Medical College, Aligarh Muslim University, Aligarh. She has completed her MBBS from Lady Hardinge Medical College, Delhi University. She is currently pursuing her thesis on Diabetic Retinopathy under the mentorship of Dr Abdul Waris. An avid learner she has a keen interest in vitreoretinal diseases and aspires to become a vitreoretinal specialist in the future. Mr Amit Mukherjee is presently pursuing his PhD in Endocrinology at the Rajiv Gandhi Centre for Diabetes \& Endocrinology, J N Medical College, Aligarh Muslim University, India, with a research interest in the field of the molecular biology of diabetic complications.

Funding

Not applicable

Availability of data and materials

Not applicable

\section{Declarations}

Ethics approval and consent to participate

Not applicable.

\section{Consent for publication}

Not applicable.

\section{Competing interests}

All authors declare that they have no competing interests.

\section{Author details}

${ }^{1}$ Institute of Ophthalmology, Jawaharlal Nehru Medical College and Hospital, Aligarh Muslim University, Aligarh, Uttar Pradesh, India. ${ }^{2}$ Rajiv Gandhi Centre for Diabetes and Endocrinology, Jawaharlal Nehru Medical College and Hospital, Aligarh Muslim University, Aligarh, Uttar Pradesh, India.

Received: 3 August 2021 Accepted: 18 November 2021

Published online: 31 January 2022

\section{References}

1. Wong TY, Sabanayagam C (2020) Strategies to tackle the global burden of diabetic retinopathy: from epidemiology to artificial intelligence. Ophthalmologica. 243(1):9-20

2. Yau JWY, Rogers SL, Kawasaki R, Lamoureux EL, Kowalski JW, BekT et al (2012) Global prevalence and major risk factors of diabetic retinopathy. Diabetes Care 35(3):556-564

3. Prasad R, Sciences O, Delhi N (2019) 2015-2019 - A SUMMARY REPORT National Programme for Control of Blindness \& Visual Impairment, Directorate General of Health Services, Ministry of Health \& Family Welfare, Government of India, New Delhi survey conducted by: https://npcbvi. gov.in/writeReadData/mainlinkFile/File341.pdf.

4. Panel APR (2017) Diabetic retinopathy PPP - updated. Am Acad Ophtalmol 2015:27-28. https://doi.org/10.1016/B978-0-323-53042-2.00251-0

5. King P, Peacock I, Donnelly R (1999) The UK prospective diabetes study (UKPDS): clinical and therapeutic implications for type 2 diabetes. $\mathrm{Br} J \mathrm{Clin}$ Pharmacol 48(5):643-8. https://doi.org/10.1046/j.1365-2125.1999.00092.x. PMID: 10594464; PMCID: PMC2014359.C1E12

6. Nathan DM, Edic D (2014) The diabetes control and complications trial / epidemiology of diabetes interventions and complications study at 30 years. overview. 37(January):9-16

7. Klein R, Knudtson MD, Lee KE, Gangnon R, Klein BEK (2010) NIH Public Access 116(3):497-503

8. Sun JK, Keenan HA, Cavallerano JD, Asztalos BF, Schaefer EJ, Sell DR et al (2011) Protection from retinopathy and other complications in patients 
with type 1 diabetes of extreme duration: the Joslin 50-year medalist study. Diabetes Care 34(4):968-974

9. Kuo JZ, Wong TY, Rotter Jl, Wiggs $J \mathrm{~L}$ (2014) Challenges in elucidating the genetics of diabetic retinopathy. JAMA Ophthalmol 132(1):96-107

10. Rema M, Saravanan G, Deepa R, Mohan V (2002) Familial clustering of diabetic retinopathy in south Indian type 2 diabetic patients. Diabet Med 19(11):910-916 [cited 2021 Apr 28]. Available from: https://pubmed.ncbi. nlm.nih.gov/12421427/

11. Jin P, Li Z, Xu X et al (2020) Analysis of association between common variants of uncoupling proteins genes and diabetic retinopathy in a Chinese population. BMC Med Genet 21:25. https://doi.org/10.1186/ s12881-020-0956-y

12. Lindholm E, Bakhtadze E, Sjögren M, Cilio CM, Agardh E, Groop L, Agardh CD (2006) The -374 T/A polymorphism in the gene encoding RAGE is associated with diabetic nephropathy and retinopathy in type 1 diabetic patients. Diabetologia49(11):2745-55. https://doi.org/10.1007/s00125006-0412-3. Epub 2006 Sep 13.

13. Fiorentino T, Prioletta A, Zuo P, Folli F (2013) Hyperglycemia-induced oxidative stress and its role in diabetes mellitus related cardiovascular diseases. Curr Pharm Des 19(32):5695-5703 [cited 2021 Feb 26]. Available from: https://pubmed.ncbi.nlm.nih.gov/23448484/

14. Priščáková P, Minárik G, Repiská V (2016) Candidate gene studies of diabetic retinopathy in human. In: Molecular biology reports, vol 43. Springer, Netherlands, pp 1327-1345

15. Henning C, Glomb MA (2016) Pathways of the Maillard reaction under physiological conditions. Glycoconj J 33:499-512 [cited 2021 Apr 30]. Available from: https://pubmed.ncbi.nlm.nih.gov/27291759/

16. Pradhan P, Upadhyay N, Tiwari A, Singh LP (2016) Genetic and epigenetic modifications in the pathogenesis of diabetic retinopathy: a molecular link to regulate gene expression. New Front Ophthalmol 2(6): 192-204

17. Stitt AW, Curtis TM (2005) Advanced glycation and retinal pathology during diabetes. Pharmacological Reports 57:156-168

18. Singh R, Barden A, Mori T, Beilin L (2001) Advanced glycation end-products: a review. Diabetologia 44:129-146 [cited 2020 Dec 27]. Available from: https://pubmed.ncbi.nlm.nih.gov/11270668/

19. Nowotny K, Jung T, Höhn A, Weber D, Grune T (2015) Advanced glycation end products and oxidative stress in type 2 diabetes mellitus. Biomolecules. 5(1):194-222

20. Kumaramanickavel G, Lakshmi V, Sripriya S (2002) Association of G82S polymorphism in the AGER gene with diabetic retinopathy in type II diabetic. Asian Indian Patients 16:391-394

21. Senatus LM, Schmidt AM (2017) The AGE-AGER axis: implications for age-associated arterial diseases. Front Genet 8:187 [cited 2021 Mar 1]. Available from: /pmc/articles/PMC5723304/

22. Li J, Cai W, Zhang W, Zhu W-F, Liu Y, Yue L-X, Zhu L-Y, Xiao J-R, Liu J-Y, Xu J (2016) Polymorphism 2184A/G in the AGER gene is not associated with diabetic retinopathy in Han Chinese patients with type 2 diabetes. J Int Med Res 44. https://doi.org/10.1177/0300060516638990

23. Mehta R, Shaw G, Masschelin P, Felix S, Otgonsuren M, Baranova A et al (2018) Polymorphisms in the receptor for advanced glycation endproducts (AGER) gene and circulating AGER levels as a susceptibility factor for non-alcoholic steatohepatitis (NASH). Hudson Bl, editor. PLoS One 13(6):e0199294 [cited 2021 Apr 30]. Available from: https://dx.plos.org/10. 1371/journal.pone.0199294

24. Ramprasad S, Radha V, Mathias RA, Majumder PP, Rao MRS, Rema M (2007) AGER gene promoter polymorphisms and diabetic retinopathy in a clinicbased population from South India. Eye. 21(3):395-401 [cited 2021 Apr 28]. Available from: https://pubmed.ncbi.nlm.nih.gov/16440015/

25. Kucukhuseyin O, Yilmaz-Aydogan H, Isbir CS, Isbir T (2012) Is there any association between GLY82 ser polymorphism of AGER gene and Turkish diabetic and non diabetic patients with coronary artery disease? Mol Biol Rep 39(4):4423-4428 [cited 2021 Apr 30]. Available from: https://pubmed. ncbi.nlm.nih.gov/21947881/

26. Serveaux-Dancer M, Jabaudon M, Creveaux I, et al (2019) Pathological Implications of Receptor for Advanced Glycation End-Product (AGER) Gene Polymorphism. Dis Markers 2019:2067353. Published 2019 Feb 4. https://doi.org/10.1155/2019/2067353

27. Schmidt AM, Yan SD, Yan SF, Stern DM (2000) The biology of the receptor for advanced glycation end products and its ligands. Biochim Biophys Acta. 1498(2-3):99-111. https://doi.org/10.1016/s0167-4889(00)00087-2.
28. Chuah YK, Basir R, Talib H, Tie TH, Nordin N (2013) Receptor for Advanced Glycation End Products and Its Involvement in Inflammatory Diseases. Int J Inflamma 2013(Art. 403460):15. https://doi.org/10.1155/2013/403460

29. Hyogo H, Yamagishi S (2008) Advanced glycation end products (AGEs) and their involvement in liver disease. Curr Pharm Des 14(10):969-972 [cited 2021 Apr 30]. Available from: https://pubmed.ncbinlm.nih.gov/ 18473847/

30. AGER (advanced glycosylation end product-specific receptor). [cited 2020 Dec 31]. Available from: http://atlasgeneticsoncology.org/Genes/ GC_AGER.html

31. Fan WY, Gu H, Yang XF, She CY, Liu XP, Liu NP (2020) Association of candidate gene polymorphisms with diabetic retinopathy in Chinese patients with type 2 diabetes. Int J Ophthalmol 13(2):301-308

32. Xiang Z, Rani U, Tajunisah I, Choong K, Fong S, Heng K (2011) Association analysis of S 429T / C and S 374T / a polymorphisms of receptor of advanced glycation end products ( AGER ) gene in Malaysian with type 2 diabetic retinopathy. Diabetes Res Clin Pract 95(3):372-377. https://doi. org/10.1016/j.diabres.2011.11.005

33. Mulrennan S, Baltic S, Aggarwal S, Wood J, Miranda A, Frost F et al (2015) The role of receptor for advanced glycation end products in airway inflammation in CF and CF related diabetes. Sci Rep 5 [cited 2021 Apr 30]. Available from: https://pubmed.ncbi.nlm.nih.gov/25754382/

34. Önal B, Özen D, Demir B, Akkan AG, Özyazgan S (2019) Receptor for advanced glycation end products gene polymorphisms in cardiac syndrome X. Biomed Reports 11(3):123-129 [cited 2021 Apr 30]. Available from: https://pubmed.ncbi.nlm.nih.gov/31423307/

35. Solan A, Kempka K, Kamiński P, Bogdzińska M, Malukiewicz G (2019) AGEs interactions with RAGE and their contribution to diabetic retinopathy. World Scientific News 119:41-51

36. Cepeda-Nieto AC, Esquivel-Contreras MT, Duran-Iñiguez F, SalinasSantander MA, Gallardo-Blanco HL, Esparza-González SC et al (2015) High prevalence of diabetic retinopathy and lack of association with integrin a2 gene polymorphisms in patients with type 2 diabetes from northeastern Mexico. Exp Ther Med 10(2):435-444 [cited 2021 Jan 26]. Available from: /pmc/articles/PMC4508982/?report=abstract

37. Xu J, Chen LJ, Yu J, Wang HJ, Zhang F, Liu Q et al (2018) Involvement of advanced Glycation end products in the pathogenesis of diabetic retinopathy. Cell Physiol Biochem 48(2):705-717

38. Balasubbu S, Sundaresan P, Rajendran A. et al (2010) Association analysis of nine candidate gene polymorphisms in Indian patients with type 2 diabetic retinopathy. BMC Med Genet 11:158. https://doi.org/10.1186/ 1471-2350-11-158

39. Jing W, Xiuyan W, Zhengxuan J, Ning B, Heting L, Liming T. The correlation between tumor necrosis factor gene polymorphism and diabetic retinopathy. [cited 2021 Jan 26]. Available from: www.biomedres.info

40. Stitt AW (2010) AGEs and diabetic retinopathy. Investig Ophthalmol Vis Sci 51(10):4867-4874

41. Ng ZX, Kuppusamy UR, Tajunisah I, Choong K, Fong S, Choon A et al (2012) 2245G / a polymorphism of the receptor for advanced glycation end-products ( $A G E R$ ) gene is associated with diabetic retinopathy in the Malaysian population, pp 289-292

42. Churchill AJ, Carter JG, Ramsden C, Turner SJ, Yeung A, Brenchley PE, Ray DW (2008) VEGF polymorphisms are associated with severity of diabetic retinopathy. Invest Ophthalmol Vis Sci 49(8):3611-3616. https://doi.org/ 10.1167/iovs.07-1383 Epub 2008 Apr 25. PMID: 18441306

43. Hudson BI, Stickland MH, Futers TS, Grant PJ (2001) Effects of novel polymorphisms in the RAGE gene on transcriptional regulation and their association with diabetic retinopathy. Diabetes 50(6):1505-1511. https:// doi.org/10.2337/diabetes.50.6.1505

44. LiW, Yanoff M, Jian B, He Z (1999) Altered mRNA levels of antioxidant enzymes in pre-apoptotic pericytes from human diabetic retinas. Cellular and molecular biology (Noisy-le-Grand, France) 45(1):59-66

45. Chen B, hua, Jiang D yong, Tang L sheng. (2006) Advanced glycation endproducts induce apoptosis involving the signaling pathways of oxidative stress in bovine retinal pericytes. Life Sci 79(11):1040-1048 [cited 2021 Jan 11]. Available from: https://pubmed.ncbi.nlm.nih.gov/16674981/

46. Yamagishi SI, Nakamura N, Suematsu M, Kaseda K, Matsui T (2015) Advanced glycation end products: a molecular target for vascular complications in diabetes. Mol Med 21:S32-S40

47. Liu L, Xiang K (1999) AGER G82S polymorphism in diabetic microangiopathy [2]. Diabetes Care 22:646 [cited 2021 May 3]. American Diabetes 
Association Inc.; Available from: https://care.diabetesjournals.org/conte $\mathrm{nt} / 22 / 4 / 646$

48. JiXiong X, BiLin X, MingGong Y, ShuQin L (2003) T429C(rs1800625) (rs1800625)(rs1800625) and-T374Apolymorphisms of AGER gene promoter are not associated with diabetic retinopathy in Chinese patients with type 2 diabetes [3]. Diabetes Care 26:2696-2697 [cited 2021 May 4]. Available from: https://care.diabetesjournals.org/content/26/9/2696

49. Yoshioka, K, Yoshida T, Takakura Y, Umekawa T, Kogure A, Toda H, Yoshikawa T (2005) Relation between polymorphisms G1704T and G82S of rage gene and diabetic retinopathy in Japanese type 2 diabetic patients. Internal medicine (Tokyo, Japan) 44(5):417-421. https://doi.org/10.2169/ internalmedicine.44.417

50. Interaction Analysis of CYBA and AGER gene polymorphisms in diabetic retinopathy patients | IOVS | ARVO Journals. [cited 2020 Oct 16]. Available from: https://iovs.arvojournals.org/article.aspx?articleid=2391588\#

51. Ng ZX, Kuppusamy UR, Tajunisah I, Fong KCS, Chua KH (2012) Association analysis of -T429C(rs1800625)(rs1800625)(rs1800625) and -T374Apolymorphisms of receptor of advanced glycation end products (AGER) gene in Malaysian with type 2 diabetic retinopathy. Diabetes Res Clin Pract 95(3):372-377

52. Kang P, Tian C, Jia C (2012) Association of AGER gene polymorphisms with type 2 diabetes mellitus, diabetic retinopathy and diabetic nephropathy. Gene. 500:1-9

53. Ng ZX, Kuppusamy UR, Poh R, Tajunisah I, Koay AC, Fong KC et al (2012) Lack of association between G82S, 1704G/T and 2184A/G of AGER gene polymorphisms and retinopathy susceptibility in Malaysian diabetic patients. Genet Mol Res 11(1):455-461

54. Yu W, Yang J, Sui W, Qu B, Huang P, Chen Y (2016) Association of genetic variants in the receptor for advanced glycation end products gene with diabetic retinopathy: a meta-analysis. Medicine (Baltimore) 95(39):e4463. https://doi.org/10.1097/MD.0000000000004463 PMID: 27684793; PMCID: PMC5265886

55. Tao D, Mai X, Zhang T, Mei Y (2017) Association between the AGER (receptor for advanced glycation end-products)-T374Agene polymorphism and diabetic retinopathy in T2DM. Rev Assoc Med Bras 63(11):971-977. https://doi.org/10.1590/1806-9282.63.11.971 [cited 2021 Apr 30]

56. Safi SZ, Qvist R, Kumar S, Batumalaie K, Ismail IS (2014) Molecular mechanisms of diabetic retinopathy, general preventive strategies, and novel therapeutic targets. Biomed Res Int 2014:801269. https://doi.org/10.1155/ 2014/801269

57. Suzuki D, Miyata T (1999) Carbonyl stress in the pathogenesis of diabetic nephropathy. Intern Med 38(4):309-314

58. Stewart MW (2010) Pathophysiology of diabetic retinopathy. Diab Retin Evide-Based Manage 2013:1-30

59. Yuan D, Yuan D, Liu Q (2012) Association of the receptor for advanced glycation end products gene polymorphisms with diabetic retinopathy in type 2 diabetes: a meta-analysis. Ophthalmologica. 227(4):223-232

60. Yang L, Wu Q, Li Y, et al (2013) Association of the receptor for advanced glycation end products gene polymorphisms and circulating RAGE levels with diabetic retinopathy in the Chinese population. J Diabetes Res 2013:264579. https://doi.org/10.1155/2013/264579

\section{Publisher's Note}

Springer Nature remains neutral with regard to jurisdictional claims in published maps and institutional affiliations.

\section{Submit your manuscript to a SpringerOpen ${ }^{\circ}$ journal and benefit from:}

- Convenient online submission

- Rigorous peer review

- Open access: articles freely available online

- High visibility within the field

- Retaining the copyright to your article

Submit your next manuscript at $\boldsymbol{\nabla}$ springeropen.com 